\title{
Construction of the Social Impact Assessment Index System and Its Conceptual Framework of Grassland Drought Disaster Based on SD Model
}

\author{
Zhenhua Dong ${ }^{1}$, Jiquan Zhang ${ }^{1}$, Zhijun Tong ${ }^{1}$, A Rong ${ }^{2}$ \\ ${ }^{1}$ School of Environment, Northeast Normal University, Institute of Natural Disaster Research, Northeast Normal \\ University, Changchun 130024, China \\ ${ }^{2}$ School of Geographical Sciences, Northeast Normal University, Changchun 130022, China
}

\section{基于 SD 的草原旱灾社会影响评价指标体系 及概念评价模型构建}

\author{
董振华 ${ }^{1}$, 张继权 ${ }^{1^{*}}$, 佟志军 ${ }^{1}$, 阿荣 ${ }^{2}$ \\ 1 东北师范大学环境学院自然灾害研究所, 长春 130024 , 中国; \\ 2 东北师范大学地理科学学院, 长春 130022 , 中国
}

\begin{abstract}
Grassland drought disaster is one of the main meteorological disasters with a wide range of influence, long duration and difficult to deal with. It not only poses a great loss and threat to the economic and ecological environment, but also causes serious secondary disasters to the society. Based on the definition and mechanism of social impact on natural disasters, we construct the conceptual framework of social impact on grassland drought disaster and the assessment model. It can help the government and other relevant institutions to grasp the influences of the drought on the grassland, and further to provide scientific support for disaster mitigation.
\end{abstract}

Key words: grassland drought disaster; social impact; conceptual framework; system dynamics model

\section{摘要}

草原早灾是一种影响范围广、持续时间长、处置救援 较为困难的气象灾害之一, 它不仅对经济、生态环境 造成巨大损失和威胁, 还会对社会造成严重的次生灾 害影响。本文以自然灾害社会影响的相关定义为基础, 根据自然灾害社会影响形成机制, 构建评价草原早灾 社会影响的概念指标体系以及评价模型。草原旱灾社
会影响评价有助于政府和其他相关机构更好地、准确 地、快速地掌握草原早灾对区域社会造成的影响程度, 为灾区的减灾救灾提供帮助和支持。

关键词: 草原旱灾; 社会影响; 概念框架; SD 模型

\section{1. 引言}

草原生态系统是陆地生态系统一个非常重要的组成 部分, 其具有特殊的生态功能, 也是保护生态环境的 天然屏障[1]。旱灾在世界上被列为第二大自然灾害, 旱灾是当前世界所面临的重大环境问题之一, 也是世 界各界关心的气候问题。随着全球变化态势日益严峻, 导致干旱灾害事件明显增加, 从而严重制约和影响区 域社会经济快速健康发展。

内蒙古地区历来是我国干旱灾害多发地区, 草原 干旱灾害是典型的干旱灾害, 具有影响范围广、持续 时间长等特点。频繁发生的草原干旱灾害愈来愈严重 制约着草原牧区经济和社会的可持续发展, 对草原牧 区牧民的生活带来极大危害。对于灾害的社会影响评 价研究起源于欧美地区, 其中最为代表的是第一个给 灾害社会影响下定义的美国研究者弗里兹, 认为灾害 的社会影响的研究是研究灾害的主要研究内容之一, 包括给社会单位带来的物质损失及对其正常职能的 破坏 [2]。后来很多专家研究者对灾害和社会互相影 响研究; 近年来对灾害社会影响、雪灾社会影响进行 
Risk Analysis and Crisis Response in Big Data Era (RAC-16)

评价研究 $[3,4]$ 。以往研究对于灾害社会影响的研究 尚属不足, 本文针对这一短板, 以草原旱灾的社会影 响为例, 建立一套草原早灾社会影响的评价体系, 这 对确保草原地区的社会持续发展及防灾减灾措施的 制定, 具有重要的意义。

\section{2. 灾害社会影响基本概念与形成机制}

\section{1. 基本概念的探究}

所谓的社会影响指的是任何公共和私人活动对人类 社会造成影响和后果, 即人们的正常生活、工作和心 理等方面发生变化, 社会影响同时还涵盖了道德、价 值观及信仰改变等文化影响。社会影响评价是具体应 用于政策或项目的社会科学研究方法, 目的在于理解 社会生活的状况、原因和结果 [5]。它所关注的是人 类环境问题, 以及其解决方法, 是帮助主决策的工具, 通过运用社会科学的知识和方法, 来分析政策或项目 所可能带来的社会变化、影响和结果, 并提供一定的 有用的知识或者对策, 以降低负面影响和实现有效管 理。总而言之, 社会影响评价作为一个决策工具, 为 机构和地区, 提供任何决策中都必须考虑的社会和文 化信息, 并且可以帮助决策者制定对地方、区域和国 家利益具有社会效益的行动过程。

灾害社会影响（social impact of disaster）是指自 然灾害对人类社会心理、社会关系、社会组织结构、 社会公共安全、社会环境、社会个体和社会家庭等非 经济层面产生的一系列作用。灾害社会影响评价主要 考虑的灾害造成的社会影响进行评价, 注重各种灾害 对非经济方面的破坏, 及恢复重建时所需求量的评价, 它强调的是社会要素的评价。灾害评估研究是灾害管 理的一项重要的基础工作, 是精确科学的进行开展减 灾救灾工作的前提 [6]。草原早灾社会影响评价是指 草原牧区受到早灾时所给社会与个体、家庭、机构、 心理、环境、秩序和稳定等方面带来的间接影响。

\section{2. 草原旱灾社会影响评价方法与技术流程}

\subsection{1. 主要研究方法}

(1) CRITIC-AHP 赋权法

CRITIC赋权法是由Diakoulaki提出的一种客观权重 赋权方法。该方法的原理是通过对利用比强度和冲突 性结合构造组合权重。具体的计算公式如下: 评价指标j所包含的信息量 $M_{j}$ 为:

$$
M_{j}=C_{j} \sum_{i=1}^{m}\left(1-r_{i j}\right)
$$

式中的 $C_{j}$ 是指标永异系数; $r_{i j}$ 为指标 $i$ 和 $j$ 的相关系数 值。 $M_{j}$ 值越大则表示指标 $\mathrm{j}$ 所包含的信息量越大, 其
权重值也越大。在此基础上对 $M_{j}$ 进行归一化处理, 即 得到指标 $\mathrm{j}$ 的客观权重值:

$$
w_{1 j}=M_{j} / \sum_{j=1}^{n} M_{j}
$$

客观赋权法不能综合考虑各个指标的实际影响 程度, 因此, 本文结合了主观赋权法AHP, 在客观赋 权的基础上结合各指标的实际情况确定权重值的大 小。层次分析法(Analytic Hierarchy Process)是美国匹 兹堡大学教授萨泰(Satty)于 20 世纪 70 年代提出的一 种将定性分析与定量分析相结合的系统分析方法, 其 本质是一种思维方法, 具体原理与计算方法参考文献。 层次分析法的主要特点是, 把要解决的问题分层系列 化, 对同一层次的各个要素, 以上一层次要素为准则, 进行两两判断、比较和计算, 以求出这些要素的权重。

根据最小相对信息熵原理构建函数, 评价指标的 综合权重值:

$$
w_{j}=\left(w_{1 j} \times w_{2 j}\right)^{\frac{1}{2}} / \sum\left(w_{1 j} \times w_{2 j}\right)^{\frac{1}{2}}
$$

式中: $w_{j}$ 为 $j$ 指标的综合权重; $w_{1 j}$ 为指标 $j$ 的 客观权重; $w_{2 j}$ 为指标 $j$ 的主观权重。

\section{（2）加权综合评价法}

在多指标综合评价中, 构建评价指标体系, 确定各个 评价指标的权重及进行无量纲标准化处理是基础, 在 此基础上需要建立综合评价模型, 将多指标的评价值 进行合成, 即通过一定的算式将多个指标对事物不同 方面的评价值综合在一起, 得到一个整体性的评价结 果。

$$
P=\sum_{i=1}^{n} F_{i} \times W_{i}
$$

式中: $P$ 表示草原早灾社会影响综合指数; $F_{i}$ 表示研 究区的某个旗、市第 $i$ 评价指标的标准值; $W_{i}$ 表示第 $i$ 个指标的权重值。

\subsection{2. 基本技术流程}

根据旱灾社会影响的形成机制与概念框架, 以草原早 灾为例建立草原旱灾社会影响评价的指标体系, 并对 其进行篮选和解释; 探讨提出草原早灾社会影响评价 的方法, 建立评价模型进行评价。其过程主要包括如 下几个步骤：1）数据的收集与处理；2）建立草原早 灾社会影响评价数据库；3）整理草原早灾社会影响 评价的感念及构建理论框架, 探寻草原早灾对社会影 响评价内部作用机制；4）基于 SD 系统动力学建模 方法, 确定和勾画出草原早灾社会影响系统边界、因 果关系图及结构流图；5）草原早灾社会影响辨识与 评价模型建立 (具体流程见图 1)。 
Risk Analysis and Crisis Response in Big Data Era (RAC-16)

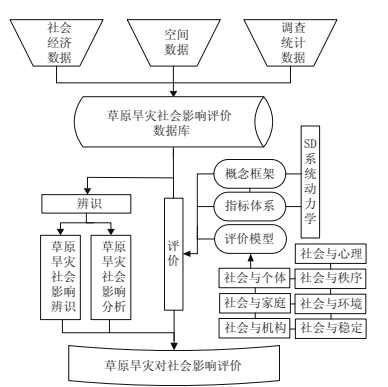

图 1 草原早灾社会影响评价流程图

\section{3. 草原早灾社会影响评价指数的建立过程}

\section{1. 草原早灾社会影响机制}

灾害系统既有自然属性, 也有社会属性。作为典型灾 害之一的旱灾也是自然与人为因素综合作用而形成、 发展的气象灾害[7]。草原早灾作为灾害的一种, 是 人类和环境相互作用的产物。草原旱灾社会影响评价 主要研究草原旱灾对社会个体其生存和发展的社会 资源与条件造成的间接损失和影响, 它贯穿于灾害发 生时的应急与灾后恢复重建全过程, 为灾后社会系统 恢复与重建提供支持 $[8]$ 。灾害影响的扩散一般是从 内到外, 由点到面。在灾害发生后, 经历破坏阶段、 处理阶段、沟通阶段和反思阶段，不同的群体、不同 的区域受到的影响不同, 最先受到影响的是遭遇早灾 的个人、家庭或机构, 不同的机构和个人在社会中所 处地位不同, 其受到的影响和反应也不同, 如对于灾 害的直接遭遇者, 除了承担生命财产损失外, 还有心 理上的创伤及未来生活的担忧; 政府组织等相关机构 则必须承担相应的政治、行政、法律和道义责任, 即 要负责受灾个体和家庭的救助、社会秩序的恢复、社 会稳定的维持等。从灾害社会影响的特性来看, 其具 有公共性、扩散的层次性、不同社会主体受到社会影 响的差异性、信息的关联性、可管理性等 [9]。基于 以上分析，文章将从社会与个体、社会与家庭、社会 与机构、社会与秩序、社会与稳定、社会与心理和社 会与环境等 7 个方面来分析草原旱灾对社会的影响 (图2)。

\section{2. 基于 SD 的草原早灾社会影响驱动机制}

草原旱灾社会响应机制的探讨基础上, 构建模型结构 和因果关系反馈关系 [10], 由社会与机构、社会与个 体、社会与家庭、社会与信心理、社会与稳定和社会 与秩序组成, 并且旱灾社会影响所涉及和包含的内容 如要素复杂, 因此建立确定和勾画出草原旱灾社会影 响系统边界、因果关系图及结构流图。

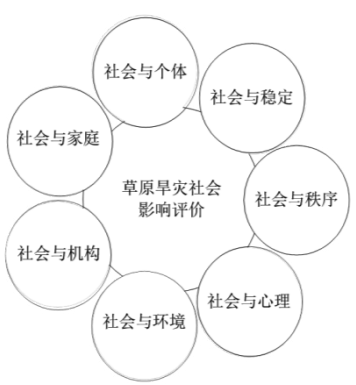

图 2 草原旱灾社会影响机制

（1）社会与机构: 灾害对政府、医疗、水电设 施、交通社会等公共服务机构造成影响, 旱灾 $\rightarrow$ 公共 设施受到影响 $\rightarrow$ 减灾救灾量 $\rightarrow$ 政府补贴, 从而导致政 府等各级机构的压力增强。

（2）社会与个体: 旱灾发生后在社会个体方面 也受到巨大影响, 家庭成员的伤亡、因灾害导致贫困 化现象进一步恶化等, 如: 旱灾 $\rightarrow$ 收入下降 $\rightarrow$ 失业率 增长; 同时区域人口结构发生变化, 受到灾害后脆弱 人口会失去劳动能。

(3) 社会与稳定: 早灾对社会的稳定影响是指 旱灾对当地的社会治安、社会稳定等方面的影响。灾 害发生后 $\rightarrow$ 在环境的刺激之下出现非理性行为 (抢劫、 暴乱、群体冲突等）－破坏社会稳定秩序。

（4）社会与家庭: 旱灾 $\rightarrow$ 财政收入 $\rightarrow$ 人均收入 $\rightarrow$ 家庭收入;

(5)社会与秩序: 旱灾 $\rightarrow$ 水域面积减少 $\rightarrow$ 停电、 停水次数增多; 还有旱灾发生后畜牧业受到影响, 导 致牧民身心疾病频发 $\rightarrow$ 医院床位紧张; 持续的高温暴 晒道路, 给人们带来不便; 物价上涨等方面引致社会 秩序紊乱。

（6）社会与心理: 旱灾发生后牧民的情绪出现 不稳定现象, 如: 旱灾 $\rightarrow$ 草场变差 $\rightarrow \rightarrow$ 储草量不够 $\rightarrow$ 牲畜死亡 $\rightarrow$ 情绪低落 $\rightarrow$ 精神和心理病变等。

（7）社会与环境: 干旱灾害的本质就是持续高 温、土壤中的水分减少, 从而影响到生产生活带来经 济损失威胁生命安全。草原是一个极为敏感, 容易受 到外界影响的生态系统, 一旦干旱程度达到定值的时 候, 土壤水分下降 $\rightarrow$ 水域面积减少 $\rightarrow$ 植被干枯死亡 $\rightarrow$ 土壤表明暴露 $\rightarrow$ 沙尘暴频发等。

综上所述, 草原旱灾社会影响评价因果关系图 (图 3) 清晰表明了各因果反馈关系, 该系统动力学 中各要素之间的联系, 为了更完善草原早灾社会影响 评价指标进行优化处理与合理的构建提供了于实际 意义和科学依据。 
Risk Analysis and Crisis Response in Big Data Era (RAC-16)

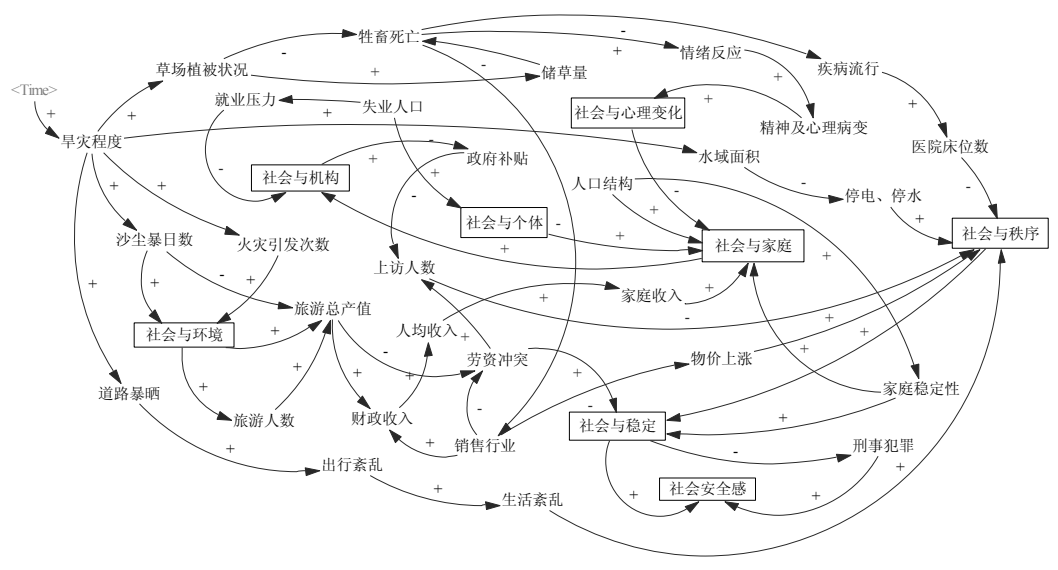

图 3 草原早灾社会影响评价因果反馈关系图

\section{3. 草原旱灾社会影响指标体系}

草原早灾是一个极为复杂的系统, 它涉及到草气候、 地貌、水文、社会经济条件等诸多要素。原早灾社会 影响指标体系构建必须与灾害学、社会科学和气象学 三大自然科学相结合。灾害社会影响评价主要评价灾 害社会个体及维持其生存和发展资源与条件造成的 损失和影响, 目前, 社会影响评价主要集中于社会个 体、家庭、机构、心理、秩序、稳定和环境 7 大领域。 应借鉴已有的研究成果[11-13], 遵循指标的广泛性、
针对性、关联性和系统层次性的原则。本文基于实地 调查, 综合考虑数据的可获取性, 构建了适用范围广、 可操作性强的草原旱灾社会影响评价体系, 可以对草 原早灾社会影响评价提供科学的参考依据。基于草原 早灾社会影响形成机理和草原旱灾社会影响评价流 程, 从草原早灾发生学角度制定草原旱灾社会影响的 概念框架(图 4), 并在此基础上构建草原旱灾社会影 响评价指标体系(表 1 )。

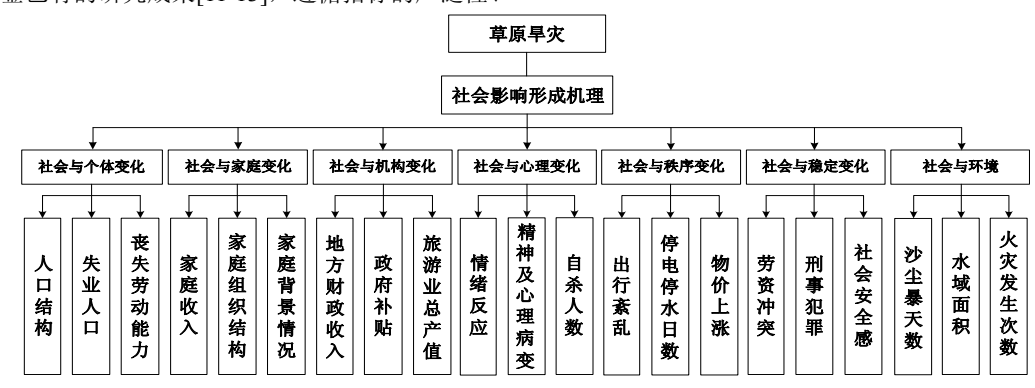

图 4 草原旱灾社会影响概念框架图

其中, 社会与个体影响评价主要分析灾害引起的 人口结构变化及对社会、经济造成的影响。受灾区域 人口变动主要有人员伤亡、外来人口走动和灾民异地 转移安置 3 个驱动因子, 造成的影响包括人口增长及 其结构变化、劳动力供给、失业率增长、经商人员流 失、特殊群体供养、社会关系破坏与重建等方面。灾
害能使灾民的家庭结构、婚姻状况和生活水平产生巨 大变化, 从而影响家庭稳定性、内部矛盾恶化、无法 生计生存, 导致家庭不和谐等因素。社会与机构对于 灾害的影响主要有两个方面: 教育机构、政府组织机 构, 具体表现在灾害发生时教育机构的应急反应、政 府组织部门的应急供给与善后安置处理。社会秩序与 
Risk Analysis and Crisis Response in Big Data Era (RAC-16)

社会稳定评价主要分析灾后使人类的出行紊乱、交通 安全隐患、生活用品不供应从而打乱正常生活规律。 稳定评价方面主要体现在劳资冲突、新来者与居民的 冲突, 影响社会的安全性和稳定性, 从而给人带来心 理上的巨大波动, 焦急、烦躁、恐慌等心理和情绪上 的反应, 甚至严重的行为错乱、心里病变、心理疾病
社会心理评价因素, 导致触犯法律、破坏社会和谐等 方面。综上所述, 此六个方面综合作用, 影响着区域 社会影响评价的大小。

表 1 草原早灾社会影响评价指标体系

\begin{tabular}{|c|c|c|}
\hline 目标层 & 准则层 & 指标层 \\
\hline \multirow[b]{7}{*}{ 草 } & \multirow{4}{*}{ 社会与个体 } & 流动人口数量 \\
\hline & & 失业人口比例 \\
\hline & & 旅游人数 \\
\hline & & 务工、经商人 \\
\hline & \multirow{3}{*}{ 社会与家庭 } & 牧民人均收入水平 \\
\hline & & 存款状况 \\
\hline & & 家庭稳定性 \\
\hline \multirow{4}{*}{$\begin{array}{l}\text { 原 } \\
\text { 早 } \\
\text { 灾 } \\
\text { 社 }\end{array}$} & \multirow{4}{*}{ 社会与机构 } & 地方财政收入 \\
\hline & & 贷款总额 \\
\hline & & 旅游业总产值 \\
\hline & & 政府补贴 \\
\hline \multirow{10}{*}{$\begin{array}{l}\text { 会 } \\
\text { 影 } \\
\text { 响 } \\
\text { 评 } \\
\text { 价 }\end{array}$} & \multirow{3}{*}{ 社会与秩序 } & 停电、停水次数 \\
\hline & & 物价上涨率 \\
\hline & & 道路维护投入 \\
\hline & \multirow{2}{*}{ 社会与稳定 } & 上访案件处理次数 \\
\hline & & 刑事犯罪次数 \\
\hline & \multirow{2}{*}{ 社会与心理 } & 心理疾病人数 \\
\hline & & 自杀人数 \\
\hline & \multirow{3}{*}{ 社会与环境 } & 沙尘暴天数 \\
\hline & & 水域面积 \\
\hline & & 火灾发生次数 \\
\hline
\end{tabular}

理, 利用加权综合评价法建立如下草原早灾社会影响 评价模型, 模型如下:

\section{4. 草原早灾社会影响评价模型}

\section{1. 草原旱灾社会影响评价指标的量化}

评价指标体系中的各指标的量纲不统一, 因此在多指 标综合评价研究中必须对数据进行标准化处理, 以消 除指标之间不同单位、不同度量的影响。本文采用极 差法对数据进行归一化处理。

对于正指标: $x_{i j}^{\prime}=\left(x_{i j}-x_{\text {min }}\right) /\left(x_{\text {max }}-x_{\text {min }}\right)$ (5) 对于负指标: $x_{i j}^{\prime}=\left(x_{\text {max }}-x_{\text {min }}\right) /\left(x_{\text {max }}-x_{\text {min }}\right)$ (6) 式中: $x_{\text {max }} 、 x_{\text {min }}$ 分别代表指标的最大值和最小值; $x_{i j}^{\prime}$ 为标准化值。

\section{2. 草原早灾社会影响评价模型建立}

$$
\begin{gathered}
G D D I I=P \times W_{p}+F \times W_{f}+I \times W_{i}+R \times W_{r}+S \times \\
W_{s}+M \times W_{m}+E \times W_{e} \\
\text { 式中: } \\
P=\sum_{i=1}^{n}\left(F_{p i} \times W_{p i}\right) ; F=\sum_{i=1}^{n}\left(F_{f i} \times W_{f i}\right) ; \\
I=\sum_{i=1}^{n}\left(F_{i i} \times W_{i i}\right) ; R=\sum_{i=1}^{n}\left(F_{r i} \times W_{r i}\right) ; \\
S=\sum_{i=1}^{n}\left(F_{s i} \times W_{s i}\right) ; M=\sum_{i=1}^{n}\left(F_{m i} \times W_{m i}\right) ; \\
E=\left(\sum_{i=1}^{n} F_{e i} \times W_{e i}\right)
\end{gathered}
$$


Risk Analysis and Crisis Response in Big Data Era (RAC-16)

式中, GDDII表示草原早灾社会影响评价指数, 它表 示草原旱灾社会影响的程度, 其值越大, 说明该区域 社会影响越大。 $W_{p} 、 W_{f} 、 W_{i} 、 W_{r} 、 W_{s} 、 W_{m} 、 W_{e}$ 分 别代表社会个体、社会家庭、社会机构、社会秩序、 社会稳定、社会心理和社会环境的权重系数根据上述 草原旱灾社会影响概念框架和自然灾害风险形成机

且, $W_{p}+W_{f}+W_{i}+W_{r}+W_{s}+W_{m}+W_{e}=1 ; P 、 F 、 I 、$ $R 、 S 、 M 、 E$ 分为社会与个体、社会与家庭、社会与 机构、社会秩序、社会与稳定、社会与心理和社会与 环境的指数。

\section{5. 结论与建议}

草原早灾以影响范围之广、持续时间之长为特点, 是 一个典型的自然灾害。本文以自然灾害社会影响的相 关定义为基础, 根据自然灾害社会影响形成机制, 讨 论草原早灾社会影响的内容与范围, 并在此基础上提 出草原早灾社会影响评价的基本概念框架, 构建草原 旱灾社会影响评价指标和模型。本文在参考了大量资 料的基础上, 得出草原旱灾社会影响评价的基本程式, 对今后草原旱灾社会影响方面的研究提供了基础依 据。本文尚只在定性方面进行了研究, 对于定量研究 指标选取上存在一定难度, 下一步研究将在本文研究 的基础上选取典型草原早灾多发区作为研究靶区, 进 行定量的草原早灾社会影响评价研究。

\section{Acknowledgements}

This study was supported by "Twelfth Five-Year" technology support program (2013BAK05B02) 、 (2013BAK05B01).

The study is financially supported by the National Nonprofit Research Program of China (No.201401015).

\section{致谢}

本研究得到了“十二五”科技支撑计划项目 (2013BAK05B02）、（2013BAK05B01）的资助。

本研究以水利部公益性行业科研专项经费项目
（201401015）为项目支撑

\section{参考文献}

[1] X.H. Li, W.J. Wu, D.B. Lv, C.H. Zhang. Research on risk assessment and regionalization of forest and grassland fires. Journal of Risk Analysis and Crisis Response, 2012, 2(1): 69-77.

[2] FRITZ, CHARLES E: Disaster, Contemporary Social Problems, New York: Harcourt, 1961

[3] 祝明, 孙舟, 唐丽霞, 于乐荣. 灾害社会影响评 估基本框架研究. 自然灾害学报, 2014, 24(4): 7-13.

[4] 乌兰, 张继权, 孙仲益. 草原雪灾社会影响评价 指标体系与概念模型: 风险分析和危机反应中的 信息技术: 中国灾害防御协会风险分析专业委员 会第六届年会论文集. 巴黎: Atlantis 出版社, 2014, 8(23-27): 650-654.

[5] 拉贝尔 $\mathrm{J}$.伯基. 社会影响评价的概念、过程和 方法. 北京: 中国环境科学出版社, 2011: 4.

[6] 李华藥, 陈蓓蓓, 刘军伟. 汶川地震灾后重建评 估现状分析. 兰州大学学报: 社会科学版, 2012, 40(1): 126-131.

[7] 解伟, 李宁, 张鹏, 吴吉东, 刘雪琴, 温玉婷.内 蒙古雪灾保险费率的厘定一一基于自然灾害系 统理论的研究. 自然灾害学报, 2012, 21(1): 163-169.

[8] 杨兴茂, 王发冬, 周晓.退耕还林工程社会影响评 价体系研究. 现在物业, 2014, 06: 21-23.

[9] 张继权, 李宁. 主要气象灾害风险评价与管理的 数量化方法及其应用. 北京: 北京师范大学出版 社, 2007: 27-244.

[10] 孙溁悦, 杨青山, 陈鹏, 张继权. 草原牧区雪灾 应急救助需求系统动力学模型与实证研究. 干早 区资源与环境, 2016, 30(06): 108-114.

[11]董振华, 张继权, 佟志军, 阿荣. 锡林郭勒盟草 原雪灾社会影响评价. 自然灾害学报, 2016, 25(2): 59-68.

[12] 李强, 史玲玲. 社会影响评价及其在我国的应用. 学术界, 2011, ( 5) : 20-27.

[13] 齐红霞, 蔡礼涁. 国外大型事件社会影响研究述 评. 旅游学刊, 2014, 29(5): 116-128.

[14] 廖永丰, 聂承静, 胡俊锋, 杨林生. 灾害救助评 估理论方法研究与展望. 灾害学, 2011, 03: 126-132. 